\title{
Rapid heating effects on grain-size, texture and magnetic properties of 3\% Si non-oriented electrical steel
}

\author{
JIAN WANG ${ }^{\dagger}$, JUN LI ${ }^{\dagger}$, XINFENG WANG ${ }^{\dagger \dagger}$, XIAOCHUAN MI ${ }^{\dagger}$ and SHENGEN ZHANG* \\ School of Materials Science and Engineering, University of Science and Technology Beijing, \\ Beijing 100083, China \\ ${ }^{\dagger}$ Baoshan Iron and Steel Co. Ltd., Shanghai 201900, China \\ ${ }^{\dagger}$ Beijing Electronic Science Vocational College, Beijing 100026, China
}

MS received 14 January 2010

\begin{abstract}
The rapid heating effects on the microstructure, texture and magnetic properties of $3 \%$ Si nonoriented electrical steel has been investigated through optical microscopy, X-ray diffraction and Epstein frame. The results show that recrystallized grains were refined with increased heating rate, caused by the nucleation rate increase, which is faster than the growth rate due to rapid hearting. With the heating rate increase, the characteristic $\{111\}$ recrystallization fibre of cold-rolled steel was depressed, but the beneficial $\langle 001\rangle / / \mathrm{RD}$ and $\langle 001\rangle / / \mathrm{ND}$ fibres were significantly strengthened. Although the grain-size decreases with heating rate increasing, the optimal magnetic properties can also be obtained through the recrystallized grain-size and texture optimization by rapid heating. In this research, we find the magnetic properties optimization can be obtained when annealed with $100^{\circ} \mathrm{C} / \mathrm{s}$ heating rate: the core loss $\left(P_{1.5 / 50}\right)$ decrease $13 \%$ and the magnetic induction $\left(B_{50}\right)$ increase $3 \%$.
\end{abstract}

Keywords. Non-oriented electrical steel; rapid heating; recrystallized grain-size; recrystallization texture; orientation distribution function (ODF); magnetic properties.

\section{Introduction}

Optimization of the magnetic properties of non-oriented electrical steel sheets has always been a priority for the electrical manufacturers (Fischer and Schneider 2003; Oshihiko et al 2008). In general, grain-size and texture are critical factors determining the magnetic properties of cold-rolled non-oriented electrical steels (Kumar et al 2003). Grain-size has an opposite effect on the hysteresis and eddy current losses, thus there is an optimal grainsize, which can help minimize the sum of hysteresis and eddy current losses (core loss) (Bertotti 2008). Grains with easy magnetic directions texture components can increase magnetic induction (Cunha and Paolinelli 2008).

It is well known that the heating rate has a strong effect on the recrystallization grain-size and texture evolution through changes in recovery and recrystallization behaviour during the final annealing treatment (Duan et al 1996; Baudouina et al 2002; Bae et al 2003; Park et al 2003; Guerenu et al 2004). Bae et al (2003) found that the mean grain-size became larger and the favourable texture was weakened with the heating rate increased from 12.5 to $21.5^{\circ} \mathrm{C} / \mathrm{s}$. Baudouin et al (2002) believed that the electrical steel magnetic properties deteriorate

\footnotetext{
*Author for correspondence (zhangshengen@ mater.ustb.edu.cn)
}

due to thermal stresses caused by high heating rates ranging from 1500 to $3000^{\circ} \mathrm{C} / \mathrm{s}$. On the other hand, Duan et al (1996) and Park et al (2003) reported that the heating rate increase in the $5-30^{\circ} \mathrm{C} / \mathrm{s}$ range has a favourable effect on magnetic properties and recrystallized microstructure.

In this paper, influences of rapid annealing with the heating rate ranging from 15 to $300^{\circ} \mathrm{C} / \mathrm{s}$ on the microstructure, texture and magnetic properties of $3 \%$ silicon cold-rolled non-oriented electrical steel was discussed.

\section{Materials and methods}

Fast heating experiments were carried out on the industrially manufactured non-oriented electrical steel with 0.0023 wt.\% C, 0.195 wt.\% Mn, 0.463 wt.\% Al and $2.93 \mathrm{wt} . \% \mathrm{Si}$, which was cold-rolled to the final thickness of $0.35 \mathrm{~mm}$ through the reduction ratio about $80 \%$. Specimens with $300 \mathrm{~mm} \times 600 \mathrm{~mm} \times 0.35 \mathrm{~mm}$ dimensions were cut from the cold-rolled steel sheet and annealed at $940^{\circ} \mathrm{C}$ for $15 \mathrm{~s}$ in $30 \% \mathrm{H}_{2}-70 \% \mathrm{~N}_{2}$ dry atmosphere using electric laboratory oven. The heating rates were $15,50,100,150$ and $300^{\circ} \mathrm{C} / \mathrm{s}$, respectively, and the cooling rate was $20^{\circ} \mathrm{C} / \mathrm{s}$, controlled by $\mathrm{H}_{2}$ flow in the oven.

The thermal cycles were recorded with a computercontrolled device using a calibrated infrared temperature 
sensors and five calibrated thermocouples welded on the sample. The temperature cures during heating the samples at $100^{\circ} \mathrm{C} / \mathrm{s}$ and $300^{\circ} \mathrm{C} / \mathrm{s}$ are presented in figures $1 \mathrm{~b}$ and c.

For the lower heating rate $100^{\circ} \mathrm{C} / \mathrm{s}$ (figure $1 \mathrm{~b}$ ) the heating rate can be controlled accurately for the curve of temperature-time is closed to a beeline. When heating rate
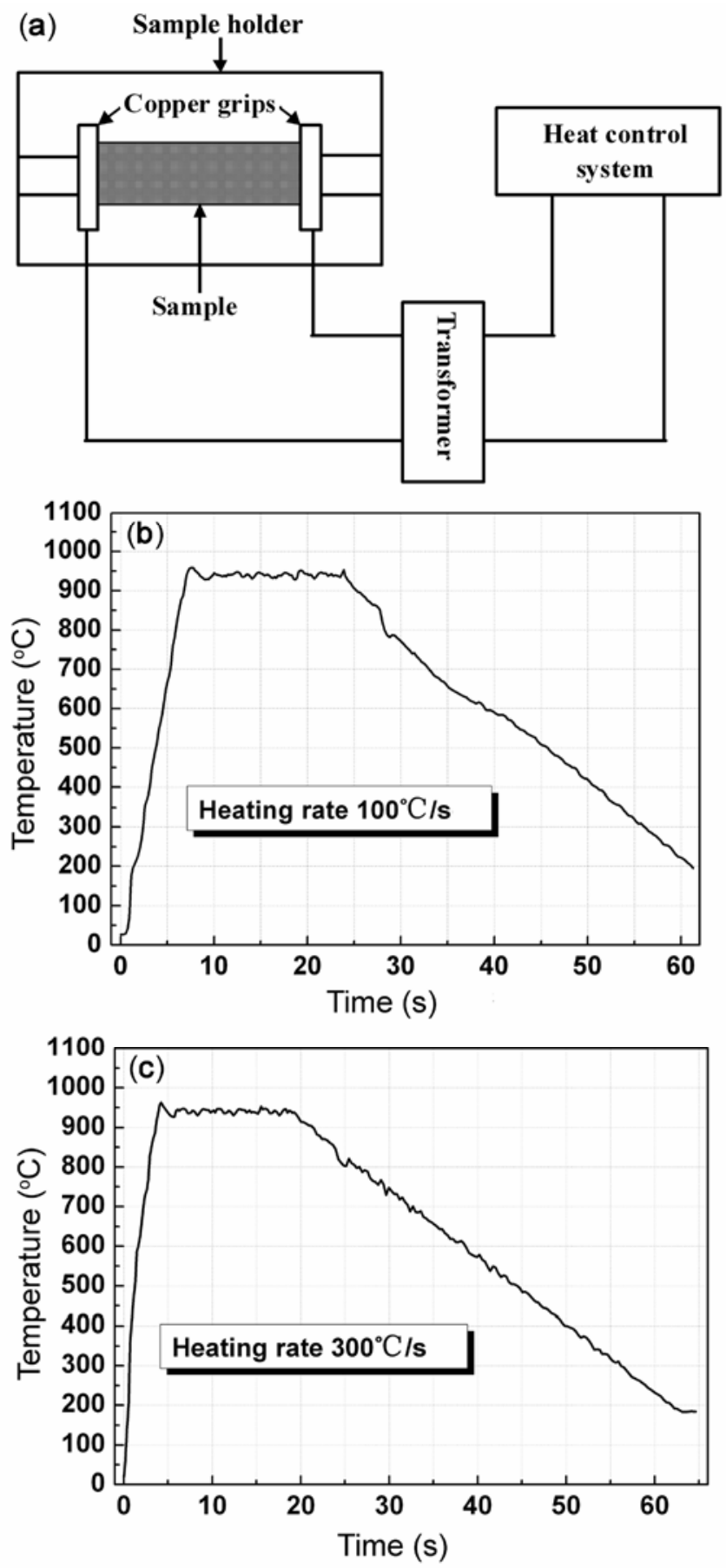

Figure 1. (a) Scheme of rapid heating experimental setup, (b) thermal cycle of treated samples with $100^{\circ} \mathrm{C} / \mathrm{s}$, (c) thermal cycle of treated samples with $300^{\circ} \mathrm{C} / \mathrm{s}$. increased to $300^{\circ} \mathrm{C} / \mathrm{s}$, the heating rate dropped appreciably when temperature approached the setting temperature for avoiding the effect of overshooting of the peak temperature. In the heating course, the ratio of temperature and time is close to $300^{\circ} \mathrm{C} / \mathrm{s}$.

The microstructures of the specimens were observed on the cross-sectional area parallel to the rolling direction using an optical microscope model of DM ILM Leica. 2\% natal solution was used as the etchant. The size of more than 200 grains in random was measured by using the standard linear intercept method. The texture measurements were performed in a section parallel to the sample surface (at $\sim 20 \%$ of the thickness from the surface). Xray diffraction was performed in a RIGAKU RINT2500/ PC XRD Diffractometer under $50 \mathrm{kV}$ and $200 \mathrm{~mA}$ with Mo radiation. The orientation distribution function (ODF) was evaluated from $\{110\},\{100\}$ and $\{211\}$ three pole figures using the Bunge series expansion method.

Magnetic induction at $5000 \mathrm{~A} / \mathrm{m}\left(B_{50}\right)$ and core losses at $1.5 \mathrm{~T}$ and $50 \mathrm{~Hz}\left(P_{1.5 / 50}\right)$ were measured by Epstein
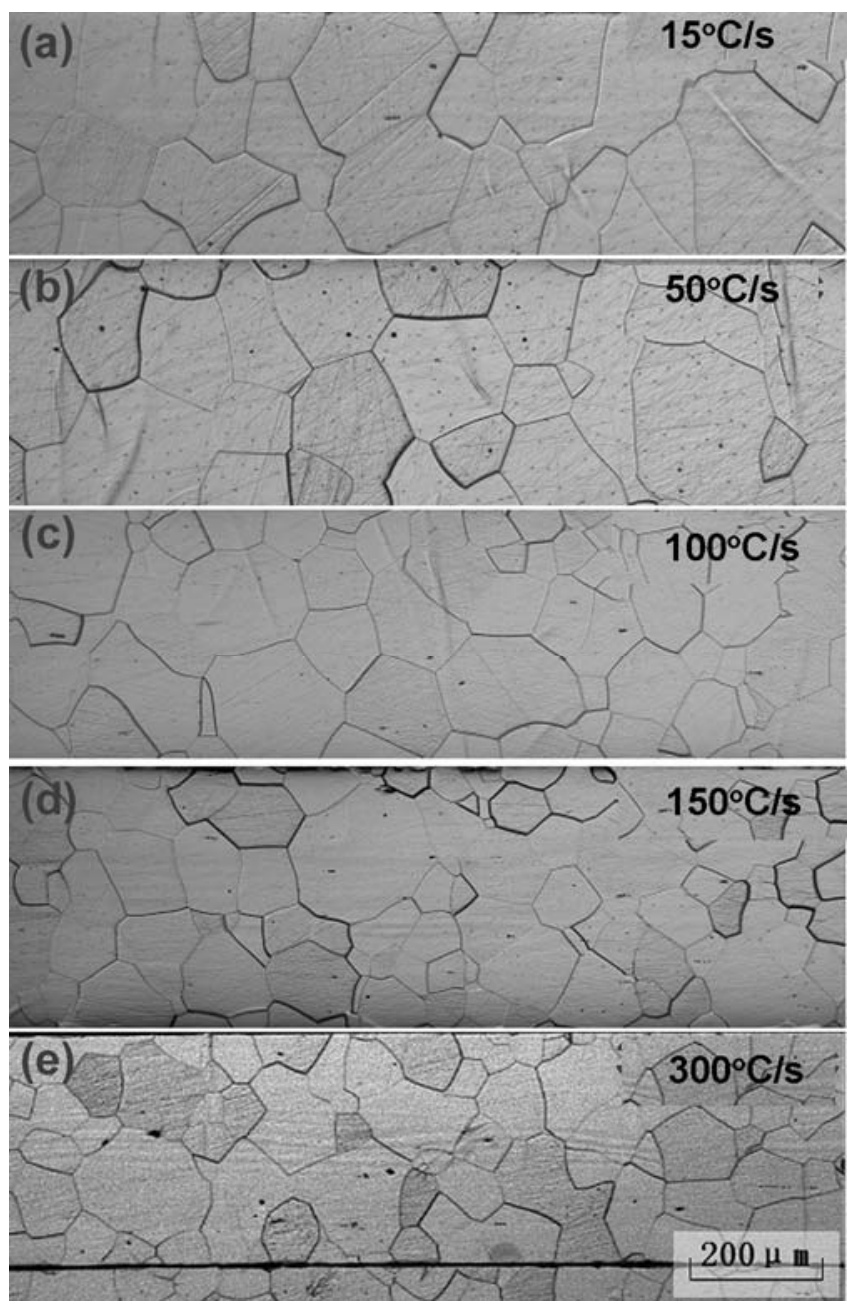

Figure 2. Optical microstructures of recrystallized specimens with different heating rates $(100 \times)$. (a) $15^{\circ} \mathrm{C} / \mathrm{s}$; (b) $50^{\circ} \mathrm{C} / \mathrm{s}$; (c) $100^{\circ} \mathrm{C} / \mathrm{s} ;$ (d) $150^{\circ} \mathrm{C} / \mathrm{s}$ and $(\mathbf{e}) 300^{\circ} \mathrm{C} / \mathrm{s}$. 
frame method on eight samples with the dimension of $180 \mathrm{~mm} \times 30 \mathrm{~mm} \times 0.35 \mathrm{~mm}$.

\section{Results and discussion}

\subsection{Rapid heating effects on the recrystallized microstructure}

Figure 2 shows microstructure of recrystallized specimens annealed at $940^{\circ} \mathrm{C}$ with heating rate ranging from 15 to $300^{\circ} \mathrm{C} / \mathrm{s}$. We can find the microstructures are composed by equiaxed grains in all samples. A decreasing trend in recrystallized grain-size is found with the heating rate increase from 15 to $300^{\circ} \mathrm{C} / \mathrm{s}$, as shown in figure 2 .

Figure 3 shows the heating rate effects on the recrystallized grain-size. We can find the mean grain-size decreases with heating rate increasing. The initial grain-size decreases from 110 to $100 \mu \mathrm{m}$ when heating rate increases from 15 to $300^{\circ} \mathrm{C} / \mathrm{s}$. The data seem to suggest that this grain refining effect has saturated beyond heating rates of $150^{\circ} \mathrm{C} / \mathrm{s}$.

During annealing process, the deformation stored energy is released in three main processes: those of recovery, recrystallization and grain coarsening (Doherty et al 1988). The size of recrystallized grain is determined by both the nucleation and growth rates (Verhoeven 1975). During fast heating, less recovery takes place than during slow heating so more stored energy is preserved in the specimen heated by fast heating before recrystallization commences. Higher stored energy increases the nucleation rate faster than the growth rate. As a result, the annealing by fast heating leads to a smaller grain-size than that by slow heating, which is in agreement with the results of other researchers (Park et al 2003; Reis et al 2003).

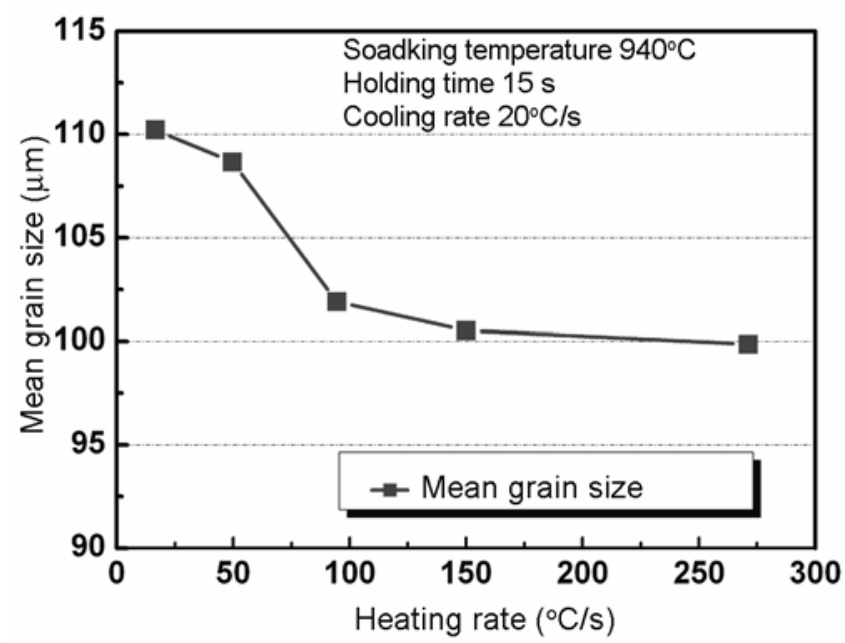

Figure 3. Mean grain-size as a function of annealing heating rates.

\subsection{Rapid heating effects on the recrystallized texture}

Figure 4 shows recrystallized texture at $\varphi_{2}=45^{\circ}$ Euler angle ODF section at different heating rates. It can be seen that the main recrystallized texture is $\gamma$-fibre, and preferred orientations mostly concentrate along the $\{111\}$ $\langle 110\rangle,\{111\}\langle 112\rangle,\{554\}\langle 225\rangle$ and $\{001\}\langle 120\rangle$ directions. During the annealing process, recrystallized texture evolution depends on the nucleation and growth rates of different orientations, which have various amounts of stored elastic energy (Every and Hatherly 1974). Recrystallization nuclei mainly concentrate on the regions with high stored elastic energy, generally, the $\{110\}$ and $\{111\}$ texture components (Park and Szpunar 2003). As a result, the main recrystallized texture components are $\langle 111\rangle / / \mathrm{ND}$ (normal direction) fibre (Ray et al 1994) (also $\gamma$-fibre with $\{111\}\langle 110\rangle$ and $\{111\}\langle 112\rangle$ main texture components).

Nevertheless, during rapid annealing, a high heating rate can reduce the release of stored elastic energy during recovery, increase the driving force for grains nucleation and coarsening and promote high angle grain boundaries migration, which lowers the orientation dependence on the recrystallization nucleation (Park et al 2003); recrystallization nuclei can also form in areas with low stored elastic energy orientation (Reis et al 2003; Sidor et al 2007 ) and finally decreasing the $\langle 111\rangle / / \mathrm{ND}$ intensity and increasing the intensity of other texture component.

Intensities of recrystallized texture components ( $\varepsilon$-fibre, $\gamma$-fibre and $\lambda$-fibre) are shown in figure 5 for different heating rates. It can be seen from figure 5 a $(\varepsilon$ fibre) that the $\{110\}\langle 001\rangle$ Goss component is strengthened when heating rate increasing to $100^{\circ} \mathrm{C} / \mathrm{s}$, while the $\{111\}\langle 112\rangle$ and $\{554\}\langle 225\rangle$ texture components are greatly weakened (figure $5 b)$. The $\{001\}\langle 120\rangle$ component also strengthened when annealed at $50-100^{\circ} \mathrm{C} / \mathrm{s}$ (figure 5c).

There are no easy magnetic directions in the $\{111\}$ planes: the $\{110\}\langle 001\rangle$ and $\{001\}\langle 120\rangle$ orientation components have $\langle 001\rangle$ easy magnetization direction along the rolling direction (Cunha and Paolinelli 2003; Park and Szpunar 2003). In a.c. motors and generators, where the magnetic field constantly rotated in a plane, the Goss texture is not adequate. The texture that should give the best magnetic properties is $\lambda$-fibre (figure $5 \mathrm{c}$ ), where the $\langle 001\rangle$ crystal direction is normal to the sheet, while the other two directions, $\langle 100\rangle$ and $\langle 010\rangle$, are distributed uniformly in the plane of sheet (Stojakovic et al 2008).

The texture optimization of non-oriented electrical steels mainly consists of avoiding the occurrence of grains with $\langle 111\rangle / / \mathrm{ND}$ fibre and generating more grains with $\langle 001\rangle / / \mathrm{RD}$ and $\langle 001\rangle / / \mathrm{ND}$ fibres (Cunha and Paolinelli 2008). Thus, rapid heating is favourable to reduce the $\gamma$-fibre intensity and increase the $\langle 001\rangle / / \mathrm{RD}$ and $\langle 001\rangle / / \mathrm{ND}$ fibres component, which is an effective way to improve magnetic properties. 

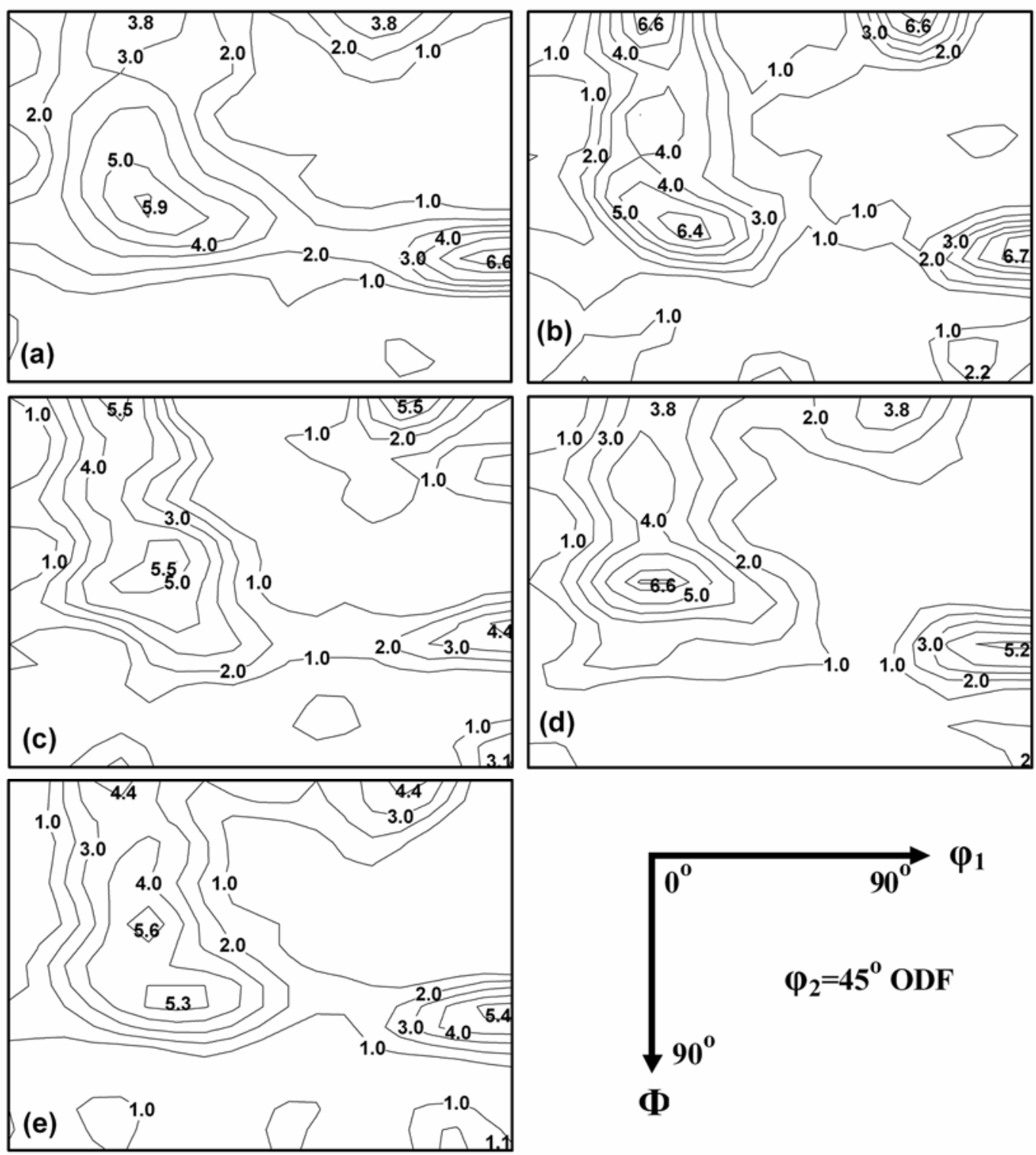

Figure 4. The $\varphi_{2}=45^{\circ}$ section of Euler space using the Bunge angular convention with different heating rates. (a) $15^{\circ} \mathrm{C} / \mathrm{s}$; (b) $50^{\circ} \mathrm{C} / \mathrm{s}$; (c) $100^{\circ} \mathrm{C} / \mathrm{s}$; (d) $150^{\circ} \mathrm{C} / \mathrm{s}$ and (e) $300^{\circ} \mathrm{C} / \mathrm{s}$.

\subsection{Rapid heating effects on the magnetic properties}

Figure 6 shows the effect of the heating rates on the core loss $\left(P_{1.5 / 50}\right)$ and magnetic induction $\left(B_{50}\right)$. It can be seen that the core losses decrease, while the heating rate increases from 15 to $100^{\circ} \mathrm{C} / \mathrm{s}$, however, core losses increase when the heating rate is higher than $100^{\circ} \mathrm{C} / \mathrm{s}$. The magnetic induction improves with the heating rate increasing from 15 to $300^{\circ} \mathrm{C} / \mathrm{s}$.

This is due to the mean grain-size decreasing with heating rate, which can reduce the classical eddy losses but increase the hysteresis losses. When grain size decreases, decrease of the grain boundary circumstance results in increasing of the hysteresis loss $\left(P_{\mathrm{h}}\right)$. The relationship between the grain-size and the domain wall width is given as follows (Min et al 2007):

$$
d^{3 / 4}=\log \left(\frac{\gamma}{K_{1}}\right)^{(\delta / 1 \cdot 32)}
$$

where $\gamma$ is the domain wall energy in a unit domain area; $K_{1}$ is the magneto-crystalline anisotropy constant and $\delta$ is the domain width. The domain width decreases with the decrease of the grain-size, resulting in the increase of hysteresis loss. As a result, a critical grain-size exists to decrease the iron loss. 

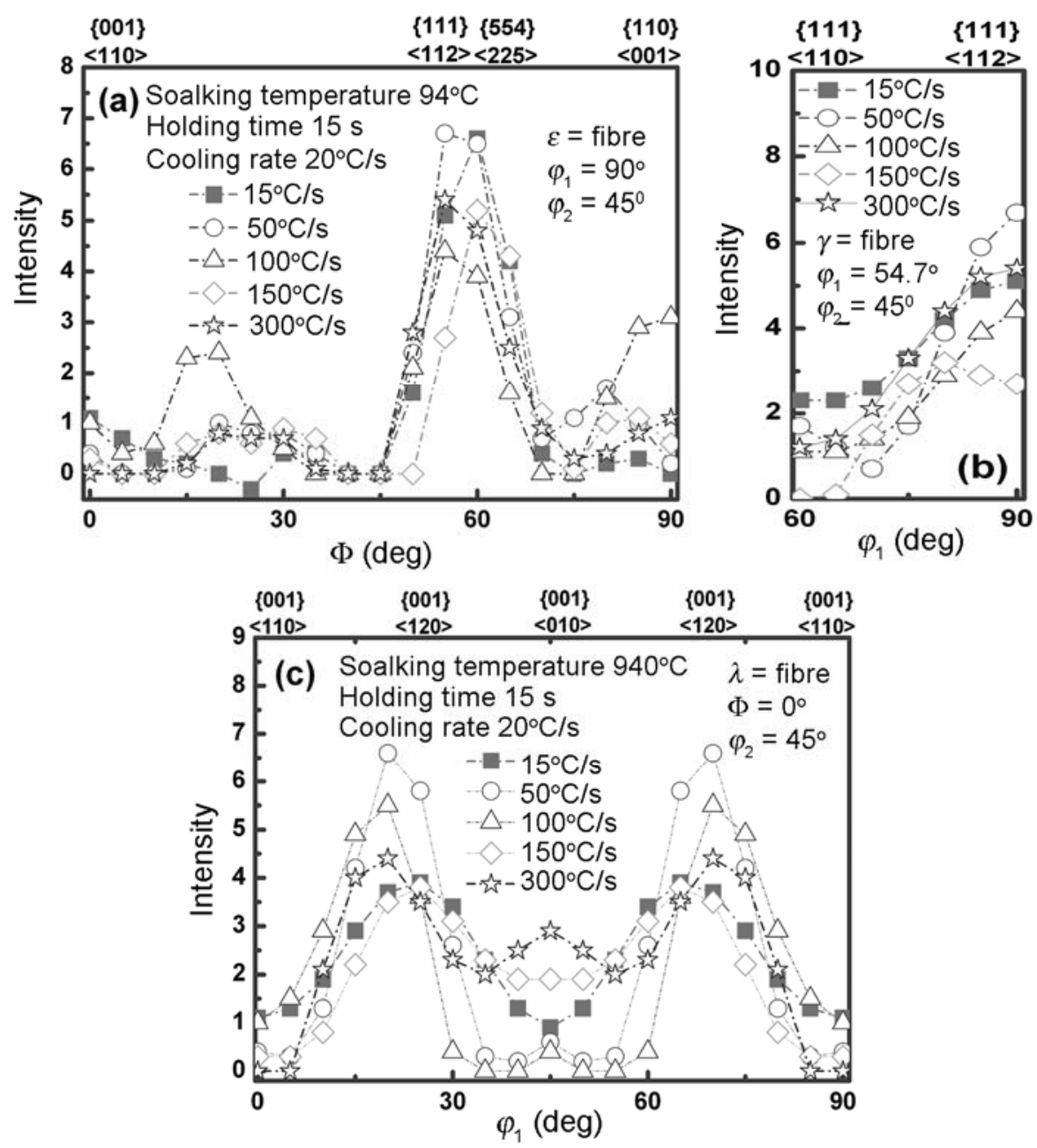

Figure 5. Intensity of different fibre texture in samples with different heating rates: (a) $\varepsilon$-fibre texture; (b) $\gamma$-fibre texture and (c) $\lambda$-fibre texture.

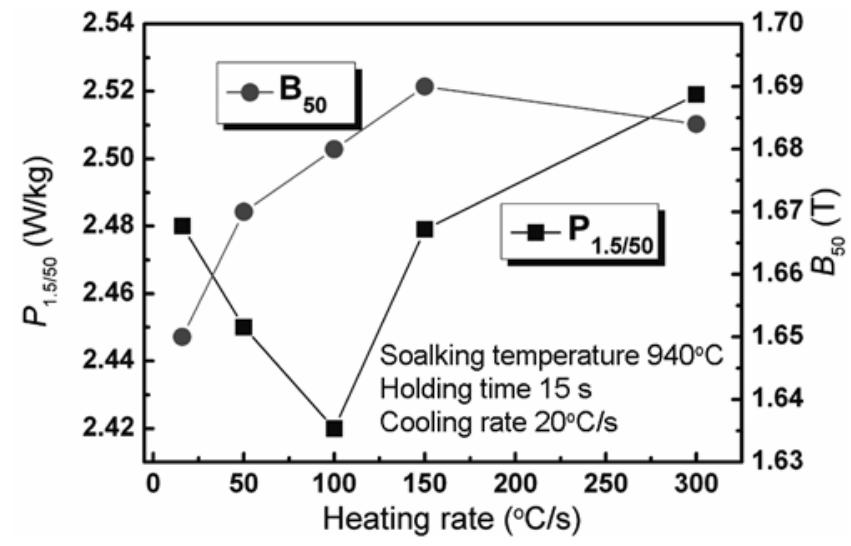

Figure 6. Effect of heating rates on core loss $\left(P_{1.5 / 50}\right)$ and magnetic induction $\left(B_{50}\right)$ for samples.

The magnetic induction increasing is due to the recrystallized texture optimization caused by rapid heating, and more investigation is needed in this area.

\section{Conclusions}

The effects of rapid heating (with heating rate ranging from 15 to $300^{\circ} \mathrm{C} / \mathrm{s}$ ) on the recrystallized grain-size, texture and magnetic properties of $3 \%$ silicon nonoriented electrical steel have been investigated with the intent to improve its magnetic properties. Based on experimental results the following conclusions can be drawn:

(I) Recrystallized grains could be refined due to high recrystallization nucleation rate caused by higher heating rate. The trend of grain refinement is seemed to saturate when heating rates are beyond $150^{\circ} \mathrm{C} / \mathrm{s}$.

(II) Recrystallization texture of $3 \%$ silicon non-oriented electrical steel could be optimized by increasing heating rate, which reduces the fraction of $\langle 111\rangle / / \mathrm{ND} \gamma$-fibre and increases the fraction of $\langle 001\rangle / / \mathrm{RD}$ and $\langle 001\rangle / / \mathrm{ND}$ fibres, since the heating rate has a great effect on the recovery, recrystallization and grain growth processes, which all can lower the orientation dependence on the recrystalliza- 
tion nucleation. In this paper, texture optimization was achieved by annealing with $100^{\circ} \mathrm{C} / \mathrm{s}$ heating rate.

(III) There are appropriate annealing heating rate $\left(100^{\circ} \mathrm{C} / \mathrm{s}\right)$ when annealed at $940^{\circ} \mathrm{C}$ and annealing time $15 \mathrm{~s}$, which simultaneously can optimize the core loss and magnetic induction. We find the magnetic properties optimization can be obtained that the core loss $\left(P_{1.5 / 50}\right)$ decrease $13 \%$ and the magnetic induction $\left(B_{50}\right)$ increase $3 \%$.

\section{Acknowledgements}

The authors gratefully acknowledge the support provided by National Natural Science Foundation of China (No. 50874010, No. 50802008), Key Projects in the National Science and Technology Pillar Program of China (No. 2009BAE74B00) and Program for New Century Excellent Talents in University (NCET).

\section{References}

Bae B K, Woo J S and Kim J K 2003 J. Magn. Magn. Mater. 254-255 373

Baudouina P, Belhadj A and Houbaert Y 2002 J. Magn. Magn. Mater. 238221

Bertotti G 2008 J. Magn. Magn. Mater. 3202436

Cunha M A and Paolinelli C P 2003 J. Magn. Magn. Mater. 254-255 379
Cunha M A and Paolinelli S C 2008 J. Magn. Magn. Mater. 320 2485

Doherty R D, Gottstein G, Hirsch J R, Huttchinson W B, Lucke K, Nes E, Wilbrandt P J, Kallend J S and Gottstein G (eds) 1988 Panel discussion on recrystallization texture, ICOTOM8 (Warrendale, PA: TMS) p. 369

Duan X, Huneus H, Kochmann T, Leuridan K, Kaczmarek R and Protat F 1996 J. Magn. Magn. Mater. 160133

Every R L and Hatherly M 1974 Texture 1183

Fischer O and Schneider J 2003 J. Magn. Magn. Mater. 254255302

Guerenu A M, Arizti F, Fuentes M D and Gutierrez I 2004 Acta Mater. 523657

Kumar P R, Samajdar I, Viswanathan N N, Singal V and Seshadri V 2003 J. Magn. Magn. Mater. 26475

Min L, Yude X, Wei W, Juan Z, Guangliang W and Yueming P 2007 Trand. Nonferrous Met. Soc. China 1774

Oshihiko O, Masaaki Y K and Atsuhito H 2008 J. Magn. Magn. Mater. 3202430

Park J T and Szpunar J A 2003 Acta Mater. 513037

Park J T, Szpunar J A and Cha S Y 2003 ISIJ Int. 431611

Ray R K, Jonas J J and Hook R E 1994 Int. Mater. Rev. 39 129

Reis A C C, Bracke L, Petrov R, Kaluba W J and Kestens L 2003 ISIJ Int. 431260

Sidor Y, Kovac F and Kvackaj T 2007 Acta Mater. 551711

Stojakovic D, Doherty R D, Kalidindi S R and Landgraf F J G 2008 Metall. Mater. Trans. A39 1738

Verhoeven J D 1975 Fundamentals of physical metallurgy (USA: John Wiley) 